\title{
Pentingnya Interaksi Hidrogen Dengan Nitrogen Backbone Di Situs FS918 Pada VEGFR2 Berdasarkan Analisis 31 Struktur Kristal VEGFR2
}

\section{The Importance of Hydrogen Interaction With Nitrogen Backbone In Site FS918 VEGFR2 Based On Analysis 31 Crystal Structure VEGFR2}

\author{
Fandriastika Maranantan ${ }^{1}$, Anintia Mara Christy ${ }^{2}$ \\ ${ }^{1}$ Molecular Modeling Center "MOLMOD.ORG" Yogyakarta, Indonesia \\ ${ }^{2}$ Akademi Farmasi Nasional Surakarta, Indonesia
}

\section{Intisari}

Dilakukan pengamatan interaksi polar terhadap 31 struktur kristal VEGFR2 menggunakan PyMOL 1.2r1. Interaksi yang terlihat berupa interaksi langsung dan tak langsung. Dari hasil pengamatan visual terlihat bahwa interaksi langsung backbone nitrogen di situs FS918 merupakan interaksi penting karena sekitar $87 \%$ dari seluruh struktur kristal VEGFR2 memiliki interaksi tersebut (dari 31 struktur kristal hanya 4 yang tidak memiliki interaksi tersebut).

Kata kunci: VEGR2, interaksi hydrogen, nitrogen backbone, situs FS918

\begin{abstract}
Polar interactions was observed from 31 VEGFR2 crystal structure using PyMOL 1.2r1.The interactions was seen in form of direct and indirect interactions. From visual observation shows that nitrogen backbone direct interaction in site FS918 is important because approximately $87 \%$ of the entire VEGFR2 crystal structure has this interaction (from 31 crystal structure only 4 that has not interaction).
\end{abstract}

\section{Keywords: VEGR2, hydrogen interaction, nitrogen backbone, FS918 site}

\section{Pendahuluan}

Neo-angiogenesis memiliki peran yang sangat penting dalam perkembangan dan kelangsungan hidup sebagian besar jenis kanker [1]. Pentargetan terhadap VEGFR menggunakan inhibitor molekul kecil merupakan salah satu stategi menghambat proses neo-angiogenesis. VEGFR2 merupakan salah satu subtipe dari reseptor VEGFR yang dipertimbangkan sebagai reseptor utama yang bertanggung jawab untuk memediasi efek psikologikal dan patologikal VEGFA pada sel endothelial [2]. VEGFR1 memiliki sepuluh kali lipat afinitas ikatan yang lebih tinggi pada VEGF, namun VEGFR1 memiliki kemampuan aktivasi intraselular signaling intermediates yang lebih rendah dibanding VEGFR2, dan akibatnya VEGFR1 dapat beraksi sebagai regulator negatif angiogenesis melalui ikatan dengan VEGF dan mencegah terikatnya VEGF ke VEGFR2 [3]. Sorafenib [4] dan Sunitinib [5] adalah molekul kecil yang dapat menghambat VEGFR2 dan telah disetujui olah FDA 
untuk pengobatan karsinoma sel ginjal [6] Beberapa molekul kecil penghambat tirosin kinase lain juga baru-baru ini dalam investigasi uji klinik fase 3 .

Jumlah data hasil struktur makromolekul hasil kristalografi sinar-x berbagai jenis protein semakin meningkat, termasuk tersedianya kristal VEGFR2 dengan beberapa molekul kecil penghambatnya. Hal ini memungkinkan untuk dilakukannya analisis untuk melihat interaksi-interaksi yang berperan penting dalam VEGFR2 terhadap molekul kecil penghambatnya. Dengan teridentifikasinya interaksi penting ini diharapkan mampu mempercepat penemuan obat penghambat VEGFR2. Pada penelitian ini dilakukan analisis terhadap interaksi polar pada 31 kristal xrey VEGFR2 dengan menggunakan PyMOL 1.2r1.

\section{Metode}

\section{Bahan}

Sejumlah 31 struktur VEGFR2 yang memiliki molekul kecil penghambat dari http://www.pdb.org/ dengan kode 2XIR [7], 4AG6, 4AGC, 4AGD, 4ASE, 4ASD [8], 2OH4 [9], 3CJF, 3CJG [10], 3DTW [11], 3EFL [12], 3EWH [13], 3VID [14], 1Y6A, 1Y6B [15], 1YWN [16], 2P2H, 2P2I [17], 2QU5, 2QU6 [18], 2RL5 [19], 3BQ8, 3BE2 [20], 3B8R [21], 3C7Q [22], 3CP9, 3CPB, 3CPC [23], $3 \mathrm{VHE}$ [24], 3U6J [25], dan 3VNT [26] digunakan sebagai referensi interaksi polar.

Alat

PyMOL1.2r1http://www.pymol.o $\mathrm{rg} /$ ) [27] digunakan untuk melihat interaksi polar pada 31 struktur kristal VEGFR2. Pengamatan komputasional dilakukan seluruhnya menggunakan Linux (Ubuntu 10.04 LTS Lucid Lynx) dengan Intel ${ }^{\circledR}$ Core ${ }^{\text {TM }}$ i5 CPU 2.67 GHz dan RAM 2.00 GB.

\section{Prosedur}

Berkas file .pdb 31 struktur kristal VEGFR2 diunduh dari http://www.pdb.org/. Masing-masing file dibuka menggunakan PyMOL 1.2r1, dilihat interaksi polar yang ada antara molekul kecil penghambat dengan binding site VEGFR2 kemudian didata. Pendataan dilakukan dengan membagi menjadi 2 golongan besar yaitu interaksi langsung dan interaksi tak langsung. Interaksi langsung yaitu interaksi ligan langsung dengan VEGFR2, sedangkan interaksi tak langsung yaitu antara ligan dengan VEGFR2 yang diperantarai air (hanya diperantarai satu molekul air). Baik interaksi langsung maupun tak langsung masing-masing dibagi lagi menjadi 2 kelas yaitu interaksi dengan backbone dan interaksi dengan residu asam amino. Kemudian interaksi backbone masingmasing dibagi kembali menjadi dua sub kelas yaitu karbonil backbone dan nitrogen backbone.

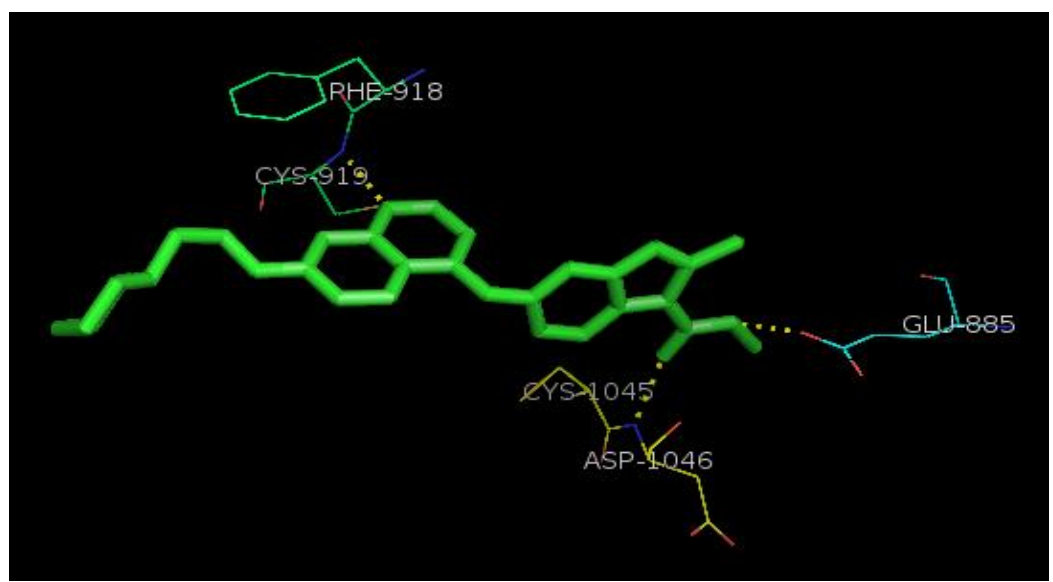

Gambar 1. Tiga Interaksi Langsung yang dominan pada kristal VEGFR2, dimodelkan dengan menggunakan struktur kristal dengan kode 2XIR 
Tabel I. Interaksi Tak Langsung 31 struktur Kristal VEGFR2

\begin{tabular}{|c|c|c|c|}
\hline \multirow{3}{*}{$\begin{array}{c}\text { Kode PDB Struktur } \\
\text { Kristal }\end{array}$} & \multicolumn{3}{|c|}{ Interaksi Tak Langsung } \\
\hline & \multicolumn{2}{|l|}{ Backbone } & \multirow{2}{*}{ Non Backbone } \\
\hline & Karbonil & Nitrogen & \\
\hline \multicolumn{4}{|l|}{ 2XIR } \\
\hline 4AG8 & Leu 840, Gly 841 & & \\
\hline $4 \mathrm{AGC}$ & Leu 840 , Gly 841 & & \\
\hline \multicolumn{4}{|l|}{ 4AGD } \\
\hline \multicolumn{4}{|l|}{ 4ASE } \\
\hline 4ASD & Leu 840 , Gly 841 & & Glu 885 \\
\hline \multicolumn{4}{|l|}{$2 \mathrm{OH} 4$} \\
\hline $3 \mathrm{CJF}$ & Arg 1030, Asn 1031 & & \\
\hline $3 \mathrm{CJG}$ & & $\begin{array}{c}\text { Asn 921, Gly } \\
920\end{array}$ & Asp 1044, Asn 921 \\
\hline \multicolumn{4}{|l|}{ 3DTW } \\
\hline \multicolumn{4}{|l|}{ 3EFL } \\
\hline $3 \mathrm{EWH}$ & & & Lys 868 \\
\hline \multicolumn{4}{|l|}{ 3VID } \\
\hline \multicolumn{4}{|l|}{$1 \mathrm{Y} 6 \mathrm{~A}$} \\
\hline 1Y6B & Arg 1030, Asn 1031 & $\begin{array}{c}\text { Gly 920, Asn } \\
921\end{array}$ & \\
\hline $1 \mathrm{YWN}$ & & & Asn 921 \\
\hline $2 \mathrm{P} 2 \mathrm{H}$ & & $\begin{array}{c}\text { Asn 923, Gly } \\
922\end{array}$ & $\begin{array}{c}\text { Asn 923, Lys 868, Asp } \\
1046\end{array}$ \\
\hline \multicolumn{4}{|l|}{ 2P2I } \\
\hline \multicolumn{4}{|l|}{ 2QU5 } \\
\hline 2QU6 & & & Asp 1046 \\
\hline 2RL5 & Arg 1027, His 1026 & & \\
\hline \multicolumn{4}{|l|}{$3 \mathrm{~B} 8 \mathrm{Q}$} \\
\hline \multicolumn{4}{|l|}{$3 \mathrm{~B} 8 \mathrm{R}$} \\
\hline \multicolumn{4}{|l|}{ 3BE2 } \\
\hline \multicolumn{4}{|l|}{$3 \mathrm{C} 7 \mathrm{Q}$} \\
\hline \multicolumn{4}{|l|}{ 3СР9 } \\
\hline \multicolumn{4}{|l|}{$3 \mathrm{CPB}$} \\
\hline \multicolumn{4}{|l|}{$3 \mathrm{CPC}$} \\
\hline \multicolumn{4}{|l|}{$3 \mathrm{VHE}$} \\
\hline \multicolumn{4}{|l|}{$3 \mathrm{U} 6 \mathrm{~J}$} \\
\hline 3VNT & $\begin{array}{c}\text { Leu 840,Gly 841, Val 899, Asn } \\
900\end{array}$ & & \\
\hline
\end{tabular}

\section{Hasil dan Pemahasan}

Pendataan awal dimulai dengan melihat jumlah interaksi tak langsung pada 31 struktur kristal VEGFR2 (Tabel I). Dari hasil analisis 31 struktur kristal VEGFR2 terlihat bahwa interaksi ligan yang berupa interaksi tak langsung merupakan interaksi yang tak penting, hal ini karena banyaknya struktur kristal yang tidak memiliki interaksi tersebut (sekitar $77 \%$ tidak terdapat interaksi tak langsung backbone karbonil, 90\% tidak memiliki interaksi tak langsung backbone nitrogen, dan $80 \%$ tidak memiliki interaksi tak langsung pada residu asam amino).

Pendataan dilanjutkan dengan melihat interaksi langsung yang terdapat pada 31 struktur kristal VEGFR2. Dari hasil pengamatan didapatkan sekitar 58\% memiliki interaksi langusng backbone karbonil, 96\% memiliki interaksi langsung backbone nitrogen, dan 74\% memiliki interaksi langsung dengan residu asam amino. Melihat persentase yang cukup besar dari 31 struktur kristal yang memiliki interaksi langsung backbone nitrogen dan interaksi langsung residu asam amino, pengamatan dilanjutkan dengan memfokuskan pada jenis interaksi yang ada di interaksi langsung backbone nitrogen dan interaksi langsung residu asam amino. Dari hasil pengamatan pada interaksi langsung residu asam amino walaupun $74 \%$ terlihat dari 31 
struktur kristal VEGFR2, jenis interaksi yang ada didominasi oleh interaksi dengan Glu 885 dan terdapat juga interaksi dengan Glu 883. Terdapat kejanggalan pada beberapa file VEGFR2, yaitu beberapa file struktur kristal ternyata memiliki penomoran yang berbeda. Oleh karena itu dilakukan penyesuaian nomor asam amino mengikuti web uniprot.org. Interaksi yang ada sebelum dan setelah penyesuaian nomor asam amino diperlihatkan pada table II. Jumlah interaksi Glu 885 dihitung dan persentasenya hanya mencapai $58 \%$ dari 31 struktur kristal VEGFR2.

Tabel II. Interaksi Langsung Struktur Kristal VEGFR2 sebelum dan selelah penyesuaian nomor asam amino

\begin{tabular}{|c|c|c|c|c|c|c|}
\hline \multirow{3}{*}{$\begin{array}{c}\text { Kode PDB } \\
\text { Struktur } \\
\text { Kristal }\end{array}$} & \multicolumn{3}{|c|}{$\begin{array}{c}\text { Interaksi Langsung Sebelum Penyesuaian } \\
\text { Nomor Asam Amino }\end{array}$} & \multicolumn{3}{|c|}{$\begin{array}{c}\text { Interaksi Langsung Setelah Penyesuaian } \\
\text { Nomor Asam Amino }\end{array}$} \\
\hline & \multicolumn{2}{|c|}{ Backbone } & \multirow{2}{*}{$\begin{array}{c}\text { Non } \\
\text { backbone }\end{array}$} & \multicolumn{2}{|c|}{ Backbone } & \multirow{2}{*}{$\begin{array}{c}\text { Non } \\
\text { Backbone }\end{array}$} \\
\hline & Karbonil & Nitrogen & & Karbonil & Nitrogen & \\
\hline 2XIR & & $A, B$ & $\mathrm{D}$ & & $A, B$ & $\mathrm{D}$ \\
\hline 4AG8 & & A & D & & A & $\mathrm{D}$ \\
\hline $4 \mathrm{AGC}$ & & A & $\mathrm{D}$ & & A & $\mathrm{D}$ \\
\hline 4AGD & $\mathrm{C}^{*}$ & $\mathrm{~B}$ & & $\mathrm{C}$ & B & \\
\hline 4ASE & & $\mathrm{A}, \mathrm{B}$ & $\mathrm{D}$ & & $\overline{A, B}$ & $\mathrm{D}$ \\
\hline 4ASD & $\mathrm{C}^{* *}$ & $\mathrm{~A}, \mathrm{~B}$ & $\mathrm{D}$ & $\mathrm{C}^{* *}$ & A,B & $\mathrm{D}$ \\
\hline $2 \mathrm{OH} 4$ & $\mathrm{C}^{*}$ & $\mathrm{~B}^{*}$ & $\mathrm{D}^{*}$ & $\mathrm{C}$ & B & $\mathrm{D}$ \\
\hline $3 \mathrm{CJF}$ & $\mathrm{C}^{*}$ & $\mathrm{~B}^{*}$ & & $\mathrm{C}$ & B & \\
\hline $3 \mathrm{CJG}$ & $\mathrm{C}^{*}$ & $\mathrm{~B}^{*}$ & $\mathrm{D}^{*}$ & $\mathrm{C}$ & B & $\mathrm{D}$ \\
\hline 3DTW & & $\mathrm{A}, \mathrm{B}$ & $E$ & & $\mathrm{~A}, \mathrm{~B}$ & $E$ \\
\hline 3EFL & & A, B & $\mathrm{D}$ & & $A, B$ & $\mathrm{D}$ \\
\hline $3 \mathrm{EWH}$ & $\mathrm{C}^{* *}$ & $\mathrm{~A}, \mathrm{~B}$ & $\mathrm{D}$ & $\mathrm{C}^{* *}$ & $A, B$ & $\mathrm{D}$ \\
\hline 3VID & $\mathrm{C}^{* *}$ & & & $\mathrm{C}^{* *}$ & & \\
\hline $1 \mathrm{Y} 6 \mathrm{~A}$ & $\mathrm{C}^{*}$ & $\mathrm{~B}^{*}$ & & $\mathrm{C}$ & $\mathrm{B}$ & \\
\hline $1 \mathrm{Y} 6 \mathrm{~B}$ & $\mathrm{C}^{*}$ & $\mathrm{~B}^{*}$ & $\mathrm{H}$ & $\mathrm{C}$ & B & $\mathrm{H}$ \\
\hline $1 \mathrm{YWN}$ & $\mathrm{C}$ & $\mathrm{A}^{*}, \mathrm{~B}^{*}$ & $\mathrm{D}^{*}$ & $\mathrm{C}$ & $\mathrm{A}, \mathrm{B}$ & $\mathrm{D}$ \\
\hline $2 \mathrm{P} 2 \mathrm{H}$ & $\mathrm{C}^{* *}$ & $\mathrm{~B}$ & & $\mathrm{C}^{* *}$ & B & \\
\hline 2P2I & & $\mathrm{A}, \mathrm{B}$ & $\mathrm{D}$ & & $\mathrm{A}, \mathrm{B}$ & $\mathrm{D}$ \\
\hline 2QU5 & $\mathrm{C}^{* *}$ & B & $\mathrm{D}$ & $\mathrm{C}^{* *}$ & B & $\mathrm{D}$ \\
\hline 2QU6 & $\mathrm{C}^{* *}$ & $A, B$ & $\mathrm{D}$ & $\mathrm{C}^{* *}$ & $A, B$ & $\mathrm{D}$ \\
\hline 2RL5 & & $\mathrm{A}, \mathrm{B}$ & $\mathrm{D}$ & & $A, B$ & $\mathrm{D}$ \\
\hline $3 \mathrm{~B} 8 \mathrm{Q}$ & & $\mathrm{A}, \mathrm{B}$ & $\mathrm{D}$ & & A, B & $\mathrm{D}$ \\
\hline 3B8R & & $\mathrm{A}, \mathrm{B}$ & $\mathrm{D}$ & & $A, B$ & $\mathrm{D}$ \\
\hline 3BE2 & & $\mathrm{A}, \mathrm{B}$ & $\mathrm{D}$ & & $A, B$ & $\mathrm{D}$ \\
\hline $3 \mathrm{C7Q}$ & $\mathrm{C}^{* *}$ & $\mathrm{~B}, \mathrm{~B}^{* *}$ & $F, G$ & $\mathrm{C}^{* *}$ & $\mathrm{~B}, \mathrm{~B}^{* *}$ & $F, G$ \\
\hline 3CP9 & $\mathrm{C}^{* *}$ & $A, B$ & & $\mathrm{C}^{* *}$ & $\mathrm{~A}, \mathrm{~B}$ & \\
\hline $3 \mathrm{CPB}$ & $\mathrm{C}^{* *}$ & $\mathrm{~A}, \mathrm{~B}$ & $\mathrm{D}$ & $\mathrm{C}^{* *}$ & $A, B$ & $\mathrm{D}$ \\
\hline $3 \mathrm{CPC}$ & $\mathrm{C}^{* *}$ & $\mathrm{~A}, \mathrm{~B}$ & & $\mathrm{C}^{* *}$ & $A, B$ & \\
\hline $3 \mathrm{VHE}$ & & A, B & & & A, B & \\
\hline 3U6J & & $\mathrm{A}, \mathrm{B}$ & G & & $\mathrm{A}, \mathrm{B}$ & $G$ \\
\hline 3VNT & $\mathrm{C}^{* *}$ & $\mathrm{~A}, \mathrm{~B}$ & $\mathrm{D}$ & $\mathrm{C}^{* *}$ & $A, B$ & $\mathrm{D}$ \\
\hline
\end{tabular}

Keterangan:

\begin{tabular}{|l|l|ll|}
\hline Backbone Nitrogen: & Backbone Karbonil: & Non Backbone: \\
\hline Asp 1046 \& Cys 1045 = A & Glu 915 \& Phe 916 = C & Glu 885 & = D \\
\hline $\begin{array}{l}\text { Asp 1044 \& Cys 1043 = } \\
\text { A* }\end{array}$ & Glu 917 \& Phe 918 = C* & Glu 883 & \\
\hline Phe 918 \& Cys 919 = B & Cys 919 \& Lys 920 = C** & Thr 916 \\
\hline Phe 916 \& Cys 917 = B* & & Glu 850 & $=$ F \\
\hline Glu 917 \& Phe 918 = B** & & Lys 868 & $=$ G \\
\hline & & Asn 921 & $=$ H \\
\hline
\end{tabular}


Pengamatan dilanjutkan dengan melihat jenis interaksi langsung backbone nitrogen dimana presentase interaksinya terbesar yaitu sekitar $96 \%$ dari 31 struktur kristal VEGFR2. Setelah penyesuaian nomor asam amino terdapat 3 jenis interaksi yang ada dalam interaksi langsung backbone nitrogen yaitu antara Asp 1046 dan Cys 1045 (interaksi A); antara Phe 918 dan Cys 919 (interaksi B); antara Glu 917 dan Phe 918 (interaksi $\left.\mathrm{B}^{* *}\right)$. Interaksi yang ada didominasi oleh interaksi A dan interaksi B, dimana interaksi A sekitar 67\% dan interaksi B sekitar $87 \%$

Situs nitrogen ini dalam artikel ini dinamakan situs FS918 terkait letaknya yang diapit oleh asam amino fenilalanin dan sistein dengan nomor urut asam amino 918 (diambil nomor yang kecil). Dari 31 kristal struktur VEGFR2 terlihat bahwa $87 \%$ memiliki interaksi terhadap nitrogen pada situs FS918 ini, sehingga dapat dikatakan bahwa interaksi dengan nitrogen backbone pada situs FS918 merupakan interaksi penting bagi ligan penghambat VEGFR2.

\section{Kesimpulan}

Interaksi dengan backbone nitrogen pada situs FS918 merupakan interaksi penting bagi ligan VEGFR2. Interaksi ini ada sekitar 87\% dari 31 kristal struktur VEGFR2 dan ligan penghambatnya yang dianalisis.

\section{Ucapan Terima Kasih}

Penulis berterima kasih kepada Enade P. Istyastono, Ph.D., Apt. (Kepala Molecular Modeling Center "MOLMOD.ORG" (www.molmod.org) Yogyakarta, Indonesia) untuk diskusi dan saran-saran yang diberikan selama penelitian berlangsung.

\section{Daftar Pustaka}

Folkman, J., Shing, Y., et al., 1992, J.Biol.Chem, 267(16):10931-4

Cross, M.J., et al., 2003, Trends.Biochem.Sci, $28(9)$ : 488-94
Ellis, L.M., Hicklin, D.J., et al., 2008, Nat.Rev.Cancer, 8(8): 579-91

Kane, R.C., et al., 2009, Oncologist, 14(1): 95-100

Goodman, V.L., et al., 2007, Clin.Cancer.Res. 13(5): 136773

Morabito, A., et al., 2006, Oncologist, 11(7): 753-64

Mctigue, M., Wickersham, J., Marrone, T., 2011, http;//www.pdb.org/

Mctigue, M., Murray, B.W., et al., 2012,

Proc.Natl.Acad.Sci.USA, http;//www.pdb.org/

Hasegawa, M., Nishigaki, et al., 2007, J.Med.Chem, 50(8):4453-4470

Harris, P.A., Boloor, A., et al, 2008, J.Med.Chem, 51(15):46324640

Kunz, R.K., Rumfelt, S., et al., 2008, J.Med.Chem, 18(18):51155117

Tasker, A.S., Patel, V.F., 2009, John Wiley \& Sons.Inc, 113-130, http;//www.pdb.org/

Cee, V.J., Cheng, A.C., et al., 2009, Bioorg.Med.Chem.Lett, 19(2):424-427

Iwata, H, Oki, H., et al, 2012, Acs.Med.Chem.Lett, 3:342346

Harris, P.A., Cheung, M., et al., 2005, J.Med.Chem, 48(5):1610-1619

Miyazaki, Y., Matsunaga, S., et al., 2005, Bioorg.Med.Chem.Lett, 15(9):2203-2207

Hodus, B.L., Geuns-Meyer, S.D., et al., 2007, J.Med.Chem, 50(4):611-626

Potashman, M.H., Bready, J., et al., 2007, J.Med.Chem, 50(18):4351-4373

La, D.S., Belzile, J., et al., 2008, J.Med.Chem, 51(6):1695-1705

Harmange, J.C., Weiss, M.M., et al., 2008, J.Med.Chem, 51(6):1649-1667

Weiss, M.M., Harmange, J.C., et al., 2008, J.Med.Chem, 51(6): 1668-1680 
Hiberg, F., Roth, G.J., et al., 2008, Cancer Res, 68(12):4774-4782

Hu, E., Tasker, A., et al., 2008, J.Med.Chem, 51(11):30653068

Oguro, Y., Miyamoto, N., et al., 2010, Bioorg.Med.Chem, 18(20):7260-7273
Norman, M.H., Liu, L., et al., 2012, Bioorg.Med.Chem, 55(5):1858-1867

Okinawa, M., Hirose, M., et al., 2012, J.Med.Chem, 55(7):3452-78

DeLano, W.L., 2002, The PyMOL User's Manual, DeLano Scientific, Palo Alto, CA, USA 
